\title{
IDENTIFICAÇÃO DAS PRÁTICAS DE GESTÃO DAS MICRO E PEQUENAS EMPRESAS: CONSTRUINDO UMA ESCALA DE MENSURAÇÃO ${ }^{1}$
}

\section{IDENTIFICATION AND CLUSTERING OF RELEVANCE FACTORS IN THE INVESTIGATION OF THE ADMINISTRATIVE PRACTICES OF THE SMALL COMPANIES}

\begin{abstract}
Bruno Tavares ${ }^{2}$
Marco Aurélio Marques Ferreira ${ }^{3}$

Afonso Augusto Teixeira de Freitas de Carvalho Lima ${ }^{4}$

RESUMO: As micro e pequenas empresas ainda representam grande desafio teórico para a ciência da Administração. Um dos aspectos refere-se à compreensão das práticas de gestão dessas organizações. Nessa direção, o presente artigo visou identificar e analisar práticas gerenciais propostas pela teoria administrativa no processo de decisão, baseando-se no nível de complexidade e de adequação da gestão ao ambiente de negócio. Para isso, delineou-se um levantamento que possibilitou avaliar os sistemas administrativos e as práticas gerencias das micro e pequenas empresas por meio de uma abordagem de pesquisa-diagnóstico. Os dados foram coletados a partir de entrevistas semi-estruturadas e observação in loco em 38 microempresas e empresas de pequeno porte na Zona da Mata Mineira. Os aspectos gerenciais foram abordados em cinco dimensões, operacionalizadas em questões representativas de variáveis de gestão. A consistência entre as variáveis de cada dimensão foi verificada pelo teste de confiabilidade Alfa de Cronbach. Como resultados, identificaram-se grupos de variáveis consistentes para as cinco dimensões e outros sete subgrupos mais específicos. Os grupos propostos podem ser utilizados na classificação de microempresas em estudos de desempenho, eficiência ou estratégia, ampliando qualitativamente as dimensões dos trabalhos nesse segmento.
\end{abstract}

PALAVRAS-CHAVE: pequenas empresas, pesquisa-diagnóstico, alfa de Cronbach.

\begin{abstract}
The small companies still represent great theoretical challenge for the science of the Administration. One of the aspects refers to the understanding of the practices of administration of those organizations. Actually, the present article had as objective to identify and to analyze practices and managerial behaviors proposed by the administrative theory in the process of decision, basing on the complexity level and of adaptation of the administration to the business system. For that, a survey was delineated to evaluate the administrative systems and the practices managements of the small companies through a research-diagnosis approach. The data were collected starting from semi-structured interviews and observation in 38 small companies in the Zona da Mata Mineira. The managerial aspects were approached in five dimensions, processed in representative subjects of administration variables. The consistence among the variables of each dimension was verified by the test of reliability (Alpha of Cronbach). The results identified groups of consistent variables for the five dimensions and other seven more specifics levels. The proposed groups can be used in the classification of small businesses in studs about performance, efficiency or strategy, contributing to the dimensions of the works in that segment.
\end{abstract}

Key words: small companies, research-diagnosis, alpha of Cronbach.

\footnotetext{
${ }^{1}$ Artigo Recebido em 02009. Revisado por pares em 22.02.2010. Recomendado em 24.03.2010 por Leomar dos Santos Editor. Publicado em 26.04.2010.

Organização Responsável pelo periódico: Universidade regional de Blumenau - FURB - www.furb.br/rn
}

\footnotetext{
${ }^{2}$ Universidade Federal de Viçosa - UFV - btavares@ufv.br

${ }^{3}$ Universidade Federal de Viçosa - UFV - $\underline{\text { marcoaurelio@ufv.br }}$

${ }^{4}$ Universidade Federal de Viçosa - UFV - $\underline{\text { afonsoli@ufv.br }}$
} 


\section{INTRODUÇÃO}

Apesar do esforço para melhor compreender as micro e pequenas empresas, compreendidas como organizações de pequeno porte, esse segmento ainda representa uma fronteira para o conhecimento administrativo. Um dos desafios a serem superados refere-se às limitações dos modelos teóricos utilizados para sua compreensão e as práticas incompletas de gestão (WELSH e WHITE, 1981; LEONE, 1999; CÊRA e ESCRIVÃO FILHO, 2003 e SANTANA e GOMES, 2008).

As origens desta dificuldade podem ser atribuídas aos modelos teóricos, geralmente importados e emanados do estudo de grandes empresas em contraposição à realidade da gestão das pequenas empresas, geralmente caracterizada pela adoção de técnicas rudimentares e simplistas ou aplicação parcial das técnicas propostas pela ciência da administração (LIMA, 2000). Este dissociação entre a abordagem teórica e a realidade empírica gera uma compreensão equivocada dos pequenos negócios.

Poucos, porém, são os autores que se preocuparam em estudar técnicas próprias para essas organizações e para o contexto nacional (BERTERO et al., 1999). De modo geral, os estudos buscam compreender a gestão de micro e pequenas empresas a partir da abordagem tradicional em administração, cuja formulação tem origem e fim nas grandes corporações multinacionais e contextualizadas em países desenvolvidos. Não é de se estranhar que a maioria das técnicas propostas para administração de pequenas empresas é resultado de adaptações simplificadas de métodos similares voltados para a realidade das grandes empresas, não considerando as particularidades nem a real utilidade que terão no contexto da pequena empresa brasileira. Somam-se a isso as questões culturais, regionais e formais que determinam as relações estabelecidas pelas organizações entre si e com o Estado. Esses fatores se diferenciam de nação para nação, dependendo do modelo econômico adotado, do arcabouço legal, da estrutura de concorrência, além dos aspectos específicos de cada setor ou atividade.

Assim, a caracterização da gestão de microempresas deve-se fundamentar em elementos que possuam a capacidade de diferenciá-las, ou seja, em um conjunto de elementos de gestão que distingam empresas que adotam práticas de gestão coerentes e daquelas que não adotam práticas de gestão ou o fazem de modo inconsistente. Alguns esforços nesse sentido foram os estudos do Sebrae (2004b) e de Viapiana (2001). Os resultados, porém, não permitem evidenciar elementos que diferenciam de modo significativo às microempresas em termos de gestão.

Nesse contexto, este estudo visou identificar a ocorrência, segundo o nível de sofisticação (ou adequação) da gestão, de práticas gerenciais no processo de decisão segundo propostas pela teoria administrativa - que permitam classificar empresas de um setor específico.

Com foco nessa situação, este estudo espera contribuir para o conhecimento sobre o desempenho das micro e pequenas empresas. Para tanto, lançou-se mão da metodologia de diagnóstico (ROESCH, 1999) do setor de salões de beleza de Ponte Nova-MG, visando a elaboração de uma escala tipo Likert válida que identifique elementos gerenciais. 


\section{CARACTERÍSTICAS DAS MICRO E PEQUENAS EMPRESAS (MPES)}

Conceituar e caracterizar as micro e pequenas empresas impõem-se como tarefa complexa, uma vez que as várias dimensões que envolvem esse segmento abre espaços para diferentes tipificações, em que qualquer constructo que se utilize não prescindirá das críticas decorrentes de isolar fatores relevantes.

Para Leone (1999), a heterogeneidade existente entre as micro e pequenas empresas consiste na maior dificuldade em estudá-las. Atribui-se a essa heterogeneidade o atraso nos estudos e pesquisas voltados a esse tipo de empresa e a dificuldade de propor teorias e conclusões adequadas e diferentes daquelas aplicadas à grande empresa.

Morelli (1994) afirma que, para que a empresa possa ser enquadrada como micro ou pequena, torna-se necessário, primeiro, a adoção de variáveis ou critérios quantitativos ou qualitativos para sua caracterização e, segundo, a determinação de parâmetros para essas variáveis.

Diversos aspectos podem ser utilizados na identificação de características que distinguem uma pequena empresa de uma unidade empresarial de maior dimensão. Dentre eles, cabe ressaltar que nem todos são quantitativos (número de funcionários, faturamento ou volume de vendas, consumo de energia, valor do ativo imobilizado, cálculo do valor adicionado, valor e estrutura do capital social, número de dirigentes etc.), merecendo destaque, também, alguns de caráter qualitativo (uso predominante do trabalho dos proprietários ou familiares, centralização do processo decisório, ausência de planejamento, uso de mão-de-obra não qualificada etc).

Para os fins deste artigo optou-se pela descrição de certos aspectos que, associados, caracterizam as micro e pequenas empresas e favorecem a compreensão da sua inserção.

$\mathrm{Na}$ sua relação com o ambiente, as micro e pequenas empresas exercem pouca ou nenhuma influência sobre o ambiente externo (LEONE, 1999 e ESCRIVÃO FILHO, 2003), sendo os esforços governamentais para o segmento enfatizados apenas nos últimos 15 anos. Nesse contexto, elas geralmente submetem-se a uma relação de complementaridade subordinada às demandas de grandes empresas (RATTNER, 1985), operando mais numa lógica de reação do que de inovação perante as mudanças e decidindo mais com foco no curto prazo. Para dar suporte a essa opção, as MPEs possuem uma estrutura de recursos que se caracterizam pela baixa intensidade de capital e alta intensidade de mão-de-obra com baixo nível de especialização (MORELI, 1994; LEONE, 1999). Alguns autores, como Solomom (1986), sugerem que a atuação em nichos de mercado oferece maior possibilidade de sobrevivência e desenvolvimento.

No âmbito interno, destaca-se a não-sistematização ou mesmo ausência de processos que registrem e armazenem dados. Isso enfraquece a tomada de decisões e reflexões sobre o seu futuro (MORELLI, 1994 e ESCRIVÃO FILHO, 2003). Uma vez que o banco de dados da pequena empresa está na cabeça do empreendedor, a gestão torna-se personalista e práticas elementares de gestão, como planejamento e controle, são precárias e comprometem a eficiência da empresa (ESCRIVÃO FILHO, 2003 e DREHER, TOMIO e ULLRICH, 2003). Soma-se a esses aspectos a formação técnico-administrativa insuficiente dos dirigentes, sendo comum o desconhecimento sobre técnicas de administração. Viapiana (2001) destaca alguns 
registros básicos que raramente são elaborados em microempresas: satisfação dos clientes, cálculo dos resultados e avaliação de funcionários. Mesmo a experiência empírica corrobora tais afirmações: um dos autores deste artigo foi procurado por um proprietário de dois estabelecimentos comerciais para saber como poderia calcular o lucro.

A baixa formalização nos procedimentos, porém, não encerra apenas aspectos negativos. O outro lado da moeda apresenta as MPEs como ideais de organização produtiva, pela agilidade na adaptação ao ambiente. A estrutura organizacional simples, nos quais procedimentos burocráticos não são necessários, permite elevada flexibilidade (LEONE, 1999; ADIZES, 2001). Essa dinâmica permite resposta mais rápida às mudanças, propicia ambiente mais favorável à inovação e, em tese, se adequaria melhor às demandas por produtos mais personalizados (NAISBITT, 1998; CASTELLS, 1999). Assim, além das funções de emprego e renda, as MPEs têm papel fundamental no desenvolvimento tecnológico e econômico.

A comunicação aberta caracteriza e sustenta a dinâmica das PMEs. Associada à elevada informalidade nas relações (MORELLI, 1994), favorece a inovação (LEONE, 1999). Além disso, sendo a relação com os agentes internos (funcionários) e externos (clientes, fornecedores) essencialmente pessoal, o papel do proprietário-gerente é reforçado como central. Essa característica também merece destaque porque suporta e reforça outras especificidades, sendo a base de sustentação da flexibilidade, que, por sua vez, contribui para a inovação. Não havendo o acúmulo de informações por meio de registros formais, nem havendo recursos suficientes para monitorar o ambiente por meio de pesquisas, são os processos de comunicação do empresário com funcionários, clientes, fornecedores e mesmo com concorrentes que permitem a obtenção de informações para tomada de decisão.

Evidencia-se a noção de que a microempresa, em muitos aspectos, mistura-se com a vida e com a pessoa do proprietário, contrariando com frequiência o princípio contábil da entidade. Esta simbiose empresa-empresário, apontada em toda a literatura especializada desde os primeiros estudos e nunca desmentida (RATTNER, 1985; FILLION, 1993; LEONE, 1999; LIMA, 2000, CÊRA e ESCRIVÃO FILHO, 2003 e SANTANA e GOMES, 2008), é o ponto central para o entendimento das pequenas empresas, existindo, inclusive, elevada influência das crenças e valores do empreendedor na organização (RATTNER, 1985; LEONE, 1999). Desse fator deriva-se que o futuro da empresa (logo, a estratégia) relaciona-se com os planos, necessidades e expectativas do empresário e de sua família. Assim, as decisões são eivadas por interesses econômicos, familiares e mesmo políticos (LEONE, 1999 e CÊRA e ESCRIVÃO FILHO, 2003).

Nesse contexto, são compreensíveis a gestão centralizada e a dificuldade de delegação do empresário pela lógica entre a pressão ambiental, a racionalidade familiar e o sistema de gestão pouco formal. A estrutura flexível da pequena empresa e a concentração das decisões na pessoa do proprietário-gerente reduzem o custo da decisão e possibilitam uma resposta ágil às mudanças externas. Isso não significa que a centralização e a falta de registros formais constituem um modelo ideal de gestão para MPEs, mas permite compreender melhor a atitude do empresário-dirigente.

Deve-se reconhecer também que, como demonstrado por Lima (2000), o entendimento da gestão de microempresas se dá a partir de sistemas de gestão desenvolvidos por e para 
grandes empresas, havendo necessidade de compreender a gestão de MPEs a partir de uma ótica mais particularizada. Isso implica considerar elementos de gestão, mas sem a expectativa de definição de modelos rígidos. Corroborando essa afirmação, Lima (2001) aponta que o entendimento da gestão em MPEs deve fundamentar-se na identificação de categorias ou grupos de itens que possam servir como diferenciadores entre organizações de mesmo segmento e mesmo porte. Portanto, a caracterização de empresas de micro e pequeno porte a partir de instrumentos teóricos desenvolvidos para as de grande porte enviesa a análise.

Para reduzir esse efeito, deve-se partir de elementos de gestão que possibilitem categorizar empresas menores em relação a outras de seu mesmo segmento. Nessa ótica, a caracterização do segmento como de baixa profissionalização (RATTNER, 1985) torna-se relativa. Em vez de inferir que o proprietário-gerente de uma empresa de pequeno porte seja um trabalhador operacional que não reflete sobre o negócio, pode-se compreendê-lo como uma pessoa que tem uma visão estratégica não-declarada, sendo mais um estrategista que corre risco do que um gestor (LEONE, 1999).

\section{PESQUISA-DIAGNÓSTICO EM PEQUENAS EMPRESAS: MOTIVOS E TÓPICOS}

Não obstante a fundamentação sobre as características das pequenas empresas, novas tecnologias e mudanças socioculturais e econômicas têm influenciado essa realidade. Dentre os recentes fatores, salientam-se a difusão das tecnologias da informação, o acirramento da concorrência e a inserção de novos empreendedores com maior nível de formação, seja em termos de educação formal, seja em termos de experiência profissional em empresas bem estruturadas (FONTOURA, 1996).

Em certo sentido, a não-profissionalização e a baixa ou não-utilização de técnicas gerenciais poderiam ser justificadas ou explicadas pela necessidade de intensa utilização de mão-de-obra para organização de dados e elevado conhecimento formal. Ambos os fatores iriam onerar ainda mais a frágil composição financeira das pequenas empresas. Atualmente, não só o acesso à informação tornou-se muito mais fácil e barato, como também a racionalização de recursos tornou-se condição para a sobrevivência, inclusive de microempresas (BERALDI e ESCRIVÃO FILHO, 2000).

Apesar de não ser possível uma conclusão definitiva, pode-se questionar se está ocorrendo maior "heterogeneização" no que se refere a aspectos gerenciais. Além disso, podem existir condicionantes que favoreçam a profissionalização do sistema gerencial dessas organizações, como a forma de inserção no mercado ou as características dos sóciosproprietários. O estudo da realidade interna das pequenas empresas pode identificar as variáveis ou conjuntos de variáveis que permitam a distinção entre empresas de um segmento específico e uma caracterização mais precisa desse segmento.

A pesquisa-diagnóstico pode ser adequada a esse propósito na medida em que descreve processos e esclarece situações da realidade organizacional específica, explorando o ambiente e identificando problemas organizacionais (ROESCH, 1999). Em outras palavras, o estudo delineado nessa perspectiva permite tanto avaliar sistemas administrativos como 
compreender a realidade organizacional por meio de informações referentes aos seus elementos constitutivos (SEIXAS e GRAVE, 2004). Mesmo assemelhando-se à modalidade de consultoria, o diagnóstico pode ser utilizado como técnica de pesquisa científica exploratória ou descritiva, favorecendo tanto a academia como as empresas participantes. No âmbito acadêmico, possibilita maior conhecimento da realidade organizacional e, do lado empresarial, possibilita a identificação de possibilidades de racionalização de sistemas administrativos.

Por fim, ressalta-se que o diagnóstico organizacional deve ser desenvolvido por meio de métodos que contemplam além das particularidades intra-funcionais, as interações interfuncionais e as características inerentes à pequena organização, pois, mesmo com transformações ambientais, as pequenas empresas continuam apresentando peculiaridades que a distinguem qualitativamente das grandes corporações.

Uma das formas mais relevantes de realização de diagnóstico são as escalas. A construção de escalas é um modelo analítico importante para o avanço do conhecimento dado que facilita a generalização do saber por meio da aplicação de um mesmo instrumento em diferentes realidades. Este delineamento foi também utilizado em pesquisas sobre pequenas empresas por Moura, Cunha e Moura (2005), Souza, Fracasso e Lopez Júnior (2008) e Garcia, Gimenez e Toledo (2008). Para pequenas empresas, além do modelo ora proposto, outras metodologias podem ser encontradas em Ribeiro Neto, Cardoso e Caulliraux (2005) e Barbosa e Cunha (2005).

\section{METODOLOGIA}

Para este estudo, realizou-se uma pesquisa descritiva, com abordagem quantitativa e qualitativa, tomando-se como sujeito social da pesquisa o principal tomador de decisão de cada organização. Os dados foram coletados a partir de entrevistas semi-estruturadas que continham perguntas fechadas e abertas e, adicionalmente, espaço para anotações das observações relevantes. A fim de evitar distorções quanto às percepções, houve a aplicação de pré-teste, seguida de adequações de linguagem e treinamentos necessários à homogeneização da coleta e validação.

A amostra foi constituída por 38 microempresas listadas entre as associadas à Associação Comercial e Industrial local e relacionadas ao Programa Capacitar do SEBRAE. A maioria dos proprietários (63\%) possui um perfil que pode ser definido como artesão, isto é, pessoas que partiram do gosto pela profissão para dar origem ao negócio. O faturamento médio é de $\mathrm{R} \$ 1.682,00$ por mês, proporcionando retirada mensal média de $\mathrm{R} \$ 584,00$. O proprietário-gerente ainda obtém $\mathrm{R} \$ 256,00$ por mês, em média, proveniente de outras atividades. De modo conjunto, os estabelecimentos faturam $\mathrm{R} \$ 55.525,00$ mensais e empregam 53 pessoas, gerando um total de 105 ocupações, incluindo os 52 sóciosproprietários.

Foram abordadas as dimensões planejamento, organização, direção e pessoas, marketing e finanças, cada uma operacionalizada pela formulação de uma ou mais questões. A elaboração e a avaliação das questões foram orientadas pelos princípios de profundidade e adequação à realidade, ou seja, a pesquisa não se restringiu à verificação de utilização de 
instrumentos ou técnicas específicas de gestão, mas também buscou perceber quais procedimentos a microempresa utiliza e se são adequadamente estruturados para obter desempenho eficiente.

As respostas foram ponderadas em escala do tipo Likert de cinco pontos, graduando-se a ocorrência dos elementos desde maneiras mais informais até as mais sistematizadas. A expectativa de se encontrar a aplicação de modelos preestabelecidos foi substituída pela análise do que é feito e sua utilidade para a empresa.

A seguir, as dimensões pesquisadas e as variáveis utilizadas para sua operacionalização são apresentados:

- Planejamento: considera a busca de informações (e o uso de tecnologia) para decisão e o estabelecimento de metas e planos. As variáveis estabelecidas foram Mecacum - avalia a utilização de mecanismos de acumulação de informações críticas para a empresa, considerando se os procedimentos são sistematizados e garantem a precisão dos registros; Acumelet - avalia a utilização de equipamentos eletrônicos para a acumulação de dados. Fica justificada sua análise, uma vez que a microinformática possibilita o tratamento sofisticado de dados a baixo custo; Metaseplanos - verifica a elaboração de metas e planos para a empresa, o horizonte temporal e a visão de futuro que o empresário possui.

- Organização: considera a divisão das tarefas, o planejamento das rotinas, a organização do espaço e aspectos legais e normativos. As variáveis consideradas na operacionalização foram Tarefasclaras - investigou a clareza na definição de tarefas; Atendimento - refere-se à manutenção do nível de serviços ofertados em termos de cumprimento do produto ofertado e pontualidade na entrega; Instalotimiz - refere-se ao nível de utilização da capacidade instalada; Regularidade - avaliou a regularidade no funcionamento da microempresa, incluindo horário de funcionamento e manutenção de rotinas; Pendências - analisa o atendimento de obrigações que legitimam o funcionamento da empresa, desde Alvará até a adimplência de dívidas bancárias; Contimpenc - analisa a elaboração de registros contábeis obrigatórios (procedimentos compulsórios), o pagamento de impostos e encargos sociais sem preocupação com a precisão dos registros ou com a sonegação. Avaliou-se o cumprimento formal das obrigações; Instalaçõesagradáveis - analisa a adequação das instalações ao funcionamento da empresa, tendo como referência as exigências legais e o nível de sofisticação que proporciona conforto aos clientes; Equipamentosutilizados - avalia o grau de adequação dos equipamentos. Como o item anterior, foi referenciado nas exigências legais e no nível de sofisticação.

- Pessoas: considera aspectos relativos a comunicação, Remuneração, Relacionamento, treinamento e capacitação. As variáveis consideradas na operacionalização foram Habprov - analisa as habilidades e a capacitação dos funcionários para a realização de tarefas; Difcon - analisa os processos de aperfeiçoamento a partir da troca de experiência entre os funcionários; Capat analisa a capacitação dos funcionários para a realização de tarefas operacionais básicas e essenciais ao funcionamento da empresa; Indep - avalia a independência 
da empresa em relação a funcionários para a realização de tarefas específicas; Relac - analisa a qualidade das relações informais entre os funcionários; Comport analisa o comportamento dos funcionários e sua adequação ao ambiente de trabalho; Remun - analisa a compatibilização entre a função realizada e a Remuneração recebida, tendo como referência o mercado de trabalho local; Reu analisa a existência de mecanismos que favorecem a participação dos funcionários com idéias para o desenvolvimento da empresa; Fluinf - analisa a eficiência da comunicação entre os que trabalham na empresa.

- Marketing: considera aspectos relativos a orientação para o mercado, produto (ou serviço), preço, localização e promoção. As variáveis consideradas na operacionalização foram Avaliasatisf - analisa a existência de procedimentos sistematizados para verificar a satisfação dos clientes; Proddiferenc - analisa a oferta de produtos diferenciados da concorrência; Fidelclientes - analisa a utilização de instrumentos com vistas à fidelização dos clientes; Clntantg - analisa a participação de clientes mais antigos no quadro de clientes atuais; Novosserv analisa a presença de novos produtos ou serviços na oferta atual, em relação ao início das atividades da empresa; Qualidade - analisa a qualidade dos serviços prestados em comparação com a concorrência. Os valores foram ajustados de modo que a ausência de percepção fosse considerada como dado perdido; Variedade - analisa a variedade dos serviços prestados em comparação com a concorrência; Preços - analisa o nível de preços praticados em relação à concorrência. Os valores foram ajustados de modo que a ausência de percepção fosse considerada como dado perdido; Localização - analisa se a localização da empresa é adequada, tendo em vista o público-alvo; Divulgação - analisa a utilização de meios formais de comunicação; Selecionadivulg - analisa os processos para a escolha dos meios de divulgação a serem utilizados.

- Finanças e contabilidade: considera aspectos relativos à existência de técnicas básicas de gestão financeira, utilização de informações financeiras e critérios de eficiência financeira. As variáveis consideradas na operacionalização foram Separa contas - avalia a separação entre contas do proprietário e da empresa; Plano retira avalia o planejamento de retirada por parte do proprietário; Faz Fluxo de Caixa avalia a elaboração do fluxo de caixa; Cntrlformais - avalia a existência de registros financeiros, como entradas e saídas; Previsão pagar contas CP - avalia se o empresário, a partir das informações financeiras disponíveis, sabia se teria condições de saldar os débitos no curtíssimo prazo; Sabe custos - avalia se o empresário conhecia a estrutura de gastos da empresa; Capital giro - avalia se o empresário utiliza informações financeiras disponíveis para conhecer a necessidade do capital de giro; Formula preço - avalia os mecanismos de formulação de preço; Calcula juros - avalia os conhecimentos elementares de matemática financeira; Compras prazo - avalia a política de compras da empresa; Fontes inadequadas - avalia as formas de financiamento utilizadas pela empresa; Financiamento específico ME - avalia o conhecimento sobre linhas de crédito específicas para microempresas, bem como sua utilização. 
Com a finalidade de identificar possíveis conjuntos de itens representativos de cada uma das dimensões nas microempresas, foi calculado o Alfa de Cronbach para verificação da confiabilidade dos grupos de perguntas. Conforme proposto por Hair Jr. et al. (2005), esse índice verifica grupo de itens múltiplos, demonstrando se os itens combinados representam de modo consistente a dimensão que se pretende investigar. No cálculo foram observados os seguintes procedimentos: a) identificação de pelo menos três itens para mensurar determinado conceito; b) os itens devem estar correlacionados positivamente e apresentar coeficiente acima de 0,3 ; e c) cálculo do alfa de Cronbach. Os cálculos foram elaborados com a utilização do software SPSS 15.0, em versão licenciada..

A intensidade de associação pode ser classificada como baixa, se alfa menor que 0,6; moderada, se alfa apresentar valor entre 0,6 e 0,7; boa, para valores entre 0,7 e 0,8 ; muito boa, se alfa apresentar valor entre 0,8 e 0,9; e excelente, para alfa acima de 0,9. Caso alfa apresente valor acima de 0,95 , deve-se verificar se os itens de fato abordam aspectos diferentes de um mesmo conceito (HAIR Jr. et al., 2005).

\section{APRESENTAÇÃO E ANÁLISE DOS RESULTADOS}

Para a melhor contextualização dos resultados, as análises serão realizadas em cinco dimensões, representadas pelos grupos: planejamento, organização operacional, pessoas, marketing e finanças.

\subsection{Planejamento}

A análise do coeficiente de Spearman apontou correlação (não-paramétrica) significativa entre todas as três variáveis entre si, sendo Mecacum-Acumelet $(0,383)$ significativa em nível de 0,05 e Mecacum-Metaseplanos $(0,633)$ e Acumelet-Metaseplanos $(0,510)$, em nível de significância de 0,01 .

Todos os itens, portanto, foram considerados para o cálculo do Alfa de Cronbach, obtendo-se resultado de 0,707 , podendo ser a consistência do grupo classificada como "boa". Em outras palavras, os itens considerados evidenciam de modo confiável a dimensão planejamento.

\subsection{Organização operacional}

A dimensão organização foi operacionalizada a partir de um conjunto elevado de itens. Para maior coerência teórica, foi dividida em dois subgrupos: um voltado para a verificação dos procedimentos operacionais e outro relacionado ao atendimento de aspectos legais e normativos. O primeiro subgrupo, denominado organização operacional, foi constituído pelos itens: Tarefasclaras; Atendimento; Instalotimiz; e Regularidade.

Uma vez que 11 (onze) das microempresas são operadas apenas pelo empresário, o coeficiente de correlação foi calculado para 27 casos e apresentou índice de correlação nãoparamétrica com as variáveis atendimento $(0,450)$ e instalotimiz $(0,467)$ para um nível de 95\% de confiança. Levando-se em conta a finalidade deste estudo, esses resultados foram considerados satisfatórios, sendo a variável tarefasclaras inserida no cálculo de consistência. 
Dentre as demais variáveis, Regularidade apresentou correlação significativa com Isntalotimiz (0,337), mas não com as demais $(0,216$ com atendimento e 0,366 com tarefas claras); por isso, não foi considerada no cálculo de consistência. A correlação entre Instalotimiz e atendimento foi de 0,470 , sendo significativa para um nível de confiança de $99 \%$.

O alfa de Cronbach, calculado no conjunto de tarefasclaras, atendimento e instalotimiz, apresentou índice de 0,738 , classificado como "bom". Isso quer dizer que os itens considerados evidenciam de modo confiável a dimensão organização operacional.

O segundo subgrupo foi denominado Legalização e Normatização e reuniu questões referentes ao atendimento de aspectos legais, como o pagamento de impostos, a formalização da empresa junto às instituições governamentais e a autorização de funcionamento emitida por órgãos como Vigilância Sanitária e Prefeitura. Constituem este grupo as variáveis: Pendências; Contimpenc; Instalaçõesagradáveis; e Equipamentosutilizados.

A variável Contimpenc não apresentou correlação significativa com nenhuma outra e foi desconsiderada do cálculo de consistência. Essa baixa correlação pode ser entendida pelo excesso de normas e regulamentos sob os quais as empresas devem atuar, associado ao baixo nível de formalização dos negócios de menor porte, sendo a própria contabilidade pouco confiável.

Entre as outras variáveis, a correlação entre Instalaçõesagradáveis e Equipamentosutilizados $(0,691)$ foi significativa em nível de 0,01 ; e desta com pendências $(0,342$ e 0,376 , respectivamente) foi significativa em nível de 0,05 . Não obstante, o alfa de Cronbach foi inferior a 0,576 , indicando nível de consistência baixo, ou seja, que o grupo de itens não se configura como adequado para "medir" o nível de formalização de microempresas. Por ser esperado um nível baixo de formalização, como é comum no segmento, a inserção de variáveis relativas aos procedimentos fiscalizados e mais observados pelos clientes do setor pesquisado (como o atendimento às exigências da Vigilância Sanitária) pode ter influenciado a configuração dos estabelecimentos, gerando resultado incoerente. Uma alternativa para outros estudos pode ser a separação dos elementos de fiscalização tributária dos outros elementos obrigatórios.

\subsection{Pessoas}

A análise de correlação apontou que as variáveis Capat, Indep e Remun são os itens passiveis de serem agrupados em um conjunto (Tabela 1), pois apresentaram correlação significativa entre si. As demais variáveis com correlações significativas formaram um conjunto de ligações esparsas.

Tabela 1 - Índices de correlação de Spearman entre variáveis na gestão de pessoas em microempresas

\begin{tabular}{c|c|c|c|c|c|c|c|c|c}
\hline & Habprov & Difcon & Capat & Indep & Relac & Comport & Remun & Reu & Fluinf \\
\hline Habprov & 1 & $-0,054$ & 0,087 & $-0,116$ & 0,317 & 0,341 & $-0,269$ & 0,057 & 0,304 \\
\hline Difcon & $-0,054$ & 1 & 0,208 & 0,32 & 0,047 & 0,036 & 0,298 & $-0,101$ & $-0,024$ \\
\hline
\end{tabular}


IDENTIFICAÇÃO DAS PRÁTICAS DE GESTÃO DAS MICRO E PEQUENAS EMPRESAS: CONSTRUINDO UMA ESCALA DE MENSURAÇÃO

\begin{tabular}{c|c|c|c|c|c|c|c|c|c}
\hline Capat & 0,087 & 0,208 & 1 & 0,576 & 0,165 & 0,283 & 0,434 & 0,580 & 0,234 \\
\hline Indep & $-0,116$ & 0,32 & 0,576 & 1 & 0,091 & 0,297 & 0,402 & 0,245 & $-0,024$ \\
\hline Relac & 0,317 & 0,047 & 0,165 & 0,091 & 1 & 0,225 & $-0,201$ & 0,364 & 0,325 \\
\hline Comport & 0,341 & 0,036 & 0,283 & 0,297 & 0,225 & 1 & $-0,109$ & 0,187 & 0,322 \\
\hline Remun & $-0,269$ & 0,298 & 0,434 & 0,402 & $-0,201$ & $-0,109$ & 1 & 0,256 & $-0,245$ \\
\hline Reu & 0,057 & $-0,101$ & 0,580 & 0,245 & 0,364 & 0,187 & 0,256 & 1 & 0,05 \\
\hline Fluinf & 0,304 & $-0,024$ & 0,234 & $-0,024$ & 0,325 & 0,322 & $-0,245$ & 0,05 & 1 \\
\hline
\end{tabular}

Fonte: Resultados da pesquisa.

O alfa de Cronbach resultante pode ser considerado "bom" $(0,712)$, porém o conjunto formado pelos três itens não indica necessariamente elementos para uma boa gestão de pessoas, e sim elementos característicos da gestão de pessoas em microempresas que são: a dependência do negócio em tarefas específicas, a multifuncionalidade dos funcionários em tarefas básicas e a Remun geralmente inferior à praticada pelo mercado.

\subsection{Marketing}

A análise das correlações de Spearman apresentadas no Anexo I indicou que as variáveis Preço Ajustado e Clientes antigos apresentaram correlação negativa ou nãosignificativa com a maioria das outras variáveis, na elaboração dos grupos específicos. No caso de "clientes antigos", pode-se entender esse comportamento devido à característica da amostra, além da baixa relação teórica com elementos de gestão.

Todas as variáveis foram reunidas no grupo Marketing Geral, inclusive Preço Ajustado e Clientes Antigos, os quais apresentaram alfa de 0,753, indicando que estas variáveis possuem boa intensidade de associação. Por ser constituído por um conjunto de itens menos homogêneos, significa que os elementos que constituem este grupo proporcionam análise mais ampla da função marketing.

Com o objetivo de identificar possíveis grupos para análises específicas, foram analisados dois outros subgrupos. $\mathrm{O}$ primeiro concentrou elementos relativos ao produto ofertado. Consideraram-se as variáveis Diferenciação, Inserção de novos serviços e Variedade. O índice resultante foi de 0,833, indicando que estes itens apresentam intensidade de associação muito boa, sugerindo que pode ser utilizado para investigar as opções estratégicas de produto de microempresas.

Por fim, elaborou-se um grupo que permitisse a avaliação mais exata dos elementos de sistema de informação de marketing, além dos quatro "Ps" (praça, produto, preço e promoção). Assim, o grupo constituiu-se das variáveis Fidelização, Avalia satisfação, Localização, Diferenciação, Novos serviços, Qualidade, Variedade, Preço e Divulgação. O alfa apresentou índice de 0,821 , indicando que há associação muito intensa entre esses 
elementos. Logo, pode-se afirmar que tais elementos também devem ser usados para caracterizar a gestão de marketing em microempresas.

\subsection{Finanças}

A análise deste grupo se deu a partir da aproximação teórica entre as variáveis, sendo utilizada a correlação de Spearman para validar tais procedimentos. A partir dos resultados , as variáveis foram classificadas em três grupos homogêneos:

- Prática financeira: é constituído de variáveis que se referem às praticas que permitem a obtenção de informações sobre a situação financeira da empresa. A mera aplicação não gera eficiência financeira, mas a favorece, uma vez que evidencia a realidade mais clara. As variáveis são: Separa Contas, Plano Retira, Cntrlformais e FluxoCaixa.

- Informações financeiras: é constituído de variáveis que representam a análise dos dados resultantes da aplicação das técnicas. As variáveis são: Sabe custos, Capital giro, Formula Preço, Previsão Pagar Contas CP e Calcula Juros.

- Decisões financeiras: é constituído de variáveis que indicam a utilização racional dos recursos. São elas: Compras Prazo, Fontes Inadequadas e Financiamento Específico ME.

Para o primeiro grupo, foi observada elevada correlação interna e intensa associação entre as variáveis Separa contas, Plano Retira, Faz Fluxo de Caixa e Registros Financeiros Formais (alfa de 0,871). Esse resultado indica que o grupo avalia de modo consistente os métodos de obtenção de informações financeiras nas microempresas. Para o grupo referente às informações financeiras, obteve-se boa correlação entre as variáveis dos grupos, e destas com as variáveis do primeiro grupo.

A partir dessa constatação, calculou-se um alfa considerando todas as variáveis e o outro considerando apenas as variáveis dos dois primeiros grupos. $\mathrm{O}$ resultado indicou que houve aumento na intensidade na associação: de 0,763 para 0,843 (acréscimo de 0,08 ponto). Levando-se em conta ainda que o alfa para as variáveis do grupo 3 foi negativo $(-0,390)$, sugere-se que o estudo da gestão financeira em microempresas concentre-se nas variáveis dos grupos 1 e 2. Para casos mais específicos, podem-se avaliar de modo separado as técnicas básicas de gestão (grupo 1; alfa de 0,871) e a utilização de informações financeiras (grupo 2) cujo alfa foi de 0,749, considerando as variáveis Sabe custos, Capital Giro, Formula Preço e desconsiderando para o cálculo de alfa Previsão Pagar Contas CP e Calcula Juros.

A seguir são apresentados os grupos gerados pelas análises e os respectivos coeficientes de validação alfa, com as variáveis consideradas.

\section{CONSIDERAÇÕES FINAIS}

Como o presente estudo comprometeu-se com a identificação de práticas e atitudes gerenciais propostas pelo arcabouço teórico, as associações permitem de forma objetiva perceber em quais dimensões existe maior poder de associação. Observa-se, de modo geral, o elevado poder de associação das variáveis escolhidas para as dimensões estudadas, o que reforça o alinhamento entre teoria e prática nos quesitos avaliados (Tabela 4). Essa 
identificação reforçará atitudes e práticas gerenciais que concorram para a exploração das técnicas e práticas em favor de ganhos de qualidade que reflitam em benefícios diretos para os empresários, com externalidades positivas para a sociedade e para o desempenho da economia regional.

Ressaltando-se o caráter exploratório deste estudo, sugerem-se futuros recortes analíticos considerando a ampliação da amostra, no intuito de possibilitar maior generalização dos resultados. Grande proveito decorrente do estudo está na possibilidade de utilização dos grupos propostos na classificação das empresas pesquisadas por meio da identificação de clusters e na verificação de correlação entre sua ocorrência e aspectos de desempenho, eficiência ou estratégia - fatores que alavancam a possibilidade de outros estudos.

Ressalta-se ainda que os resultados indicam a necessidade de reformulação dos conceitos, não para sua invalidação. Ao contrário, reforça a concepção de que a administração não é idêntica para organizações de todo e qualquer porte, devendo haver um esforço continuado para melhor compreender as pequenas empresas considerando-as como uma nova realidade carente e profícua para estudos.

Neste processo, a aproximação entre academia e empresariado cumpre função nuclear, cabendo à ciência prover estudos abrangentes e contínuos sobre o segmento, de modo que supere o modelo de "ciência atrofiada", como caracterizada a administração por Wood (2003) e ao empresariado o aprimoramento constante de sua prática.

Por fim, salienta-se que a obtenção dos dados foi facilitada pela organização social das empresas pelo Sebrae-MG e pela Associação Comercial local, disseminando o entendimento de que a pesquisa resultaria em benefícios reais para todos os envolvidos. A interação entre essas instituições e a universidade responsável pelo diagnóstico favoreceu a obtenção de dados via avaliação in loco, além da opinião dos empresários. 


\begin{tabular}{|c|c|c|c|c|}
\hline Conjunto & Alpha & $\begin{array}{l}\text { Número } \\
\text { de itens }\end{array}$ & $\begin{array}{l}\text { Classifica } \\
\text { ção }\end{array}$ & Itens \\
\hline Planejamento & 0,707 & 3 & Boa & $\begin{array}{l}\text { Mecanismos de Acumulação, Acumulação } \\
\text { Eletrônica e Elaboração de Metas e Planos. }\end{array}$ \\
\hline Organização operacional & 0,738 & 3 & Boa & $\begin{array}{l}\text { Clareza na Divisão de Tarefas; Confiabilidade } \\
\text { no Nível de Atendimento e Utilização da } \\
\text { Capacidade Instalada. }\end{array}$ \\
\hline Legalização & 0,576 & 3 & Fraca & $\begin{array}{l}\text { Cumprimento das Exigências Formais, } \\
\text { Adequação das Instalações e Adequação dos } \\
\text { Equipamentos. }\end{array}$ \\
\hline Pessoas & 0,712 & 3 & Boa & $\begin{array}{l}\text { Independência do Salão, Capacidade de } \\
\text { Atendimento e Remunerção. }\end{array}$ \\
\hline Marketing Geral & 0,753 & 10 & Boa & Todos. \\
\hline Subgrupo 01 Produto & 0,833 & 3 & Muito boa & $\begin{array}{l}\text { Diferenciação por Produto; Novos Serviços; } \\
\text { Variedade (Ajustada). }\end{array}$ \\
\hline Marketing Geral 02 & 0,821 & 9 & Muito boa & $\begin{array}{l}\text { Localização, Fidelização, Avalia Satif, } \\
\text { Divulgação, Diferenciação, Novos Serviços, } \\
\text { Qualidade, Variedade e Preço. }\end{array}$ \\
\hline Gestão financeira & 0,763 & 12 & Boa & Todas \\
\hline $\begin{array}{l}\text { Técnicas e informações } \\
\text { financeiras }\end{array}$ & 0,843 & 9 & Muito boa & $\begin{array}{l}\text { Separa Contas; Plano Retira, Cntrlformais e } \\
\text { Fluxocaixa, Previsão Pagar Contas CP; Sabe } \\
\text { Custos; Capital Giro; Formula Preço e Calcula } \\
\text { Juros. }\end{array}$ \\
\hline Técnicas básicas & 0,871 & 4 & Muito boa & $\begin{array}{l}\text { Separa Contas; Plano Retira; Faz Fluxo de } \\
\text { Caixa; Registros Financeiros Formais. }\end{array}$ \\
\hline Informações financeiras & 0,662 & 5 & Moderada & $\begin{array}{l}\text { Sabe Custos; Capital Giro, Formula Preço, } \\
\text { Previsão Pagar Conta, Calcula Juros. }\end{array}$ \\
\hline Informações financeiras 2 & 0,749 & 3 & Boa & Sabe Custos; Capital Giro Formula Preço. \\
\hline
\end{tabular}

Fonte: Resultados da pesquisa. 
REFERÊNCIAS

BARBOSA, Fábio Eduardo de Freitas; CUNHA, João Carlos da. Instrumento para auxiliar no diagnóstico em sistemas de Gestão da Qualidade baseados na NRB ISSO 9001:2000In: EGEPE - ENCONTRO DE ESTUDOS SOBRE EMPREENDEDORISMO E GESTÃO DE PEQUENAS EMPRESAS. 4. 2005, Curitiba, Anais...Curitiba, 2005.BERALDI, L. C.; ESCRIVÃO FILHO, E. Impacto da tecnologia de informação na gestão de pequenas empresas. Ciência da Informação, Brasília, v. 29, n. 1, p. 46-50, jan./abr. 2000.

BERTERO, Carlos Osmar; CALDAS, Miguel Pinto; WOOD JR, Thomaz. Produção científica em administração de empresas: provocações, insinuações e contribuições para um debate local. Revista de Administração Contemporânea, v.3, n.1, p.147-178, 1999.

CÊRA, Kristiane e ESCRIVÃO FILHO, Edmundo. Particularidades de gestão da pequena empresa: condicionantes ambientais, organizacionais e comportamentais do dirigente. In: EGEPE - ENCONTRO DE ESTUDOS SOBRE EMPREENDEDORISMO E GESTÃO DE PEQUENAS EMPRESAS. 3., 2003, Brasília. Anais... Brasília: UEM/UEL/UnB, 2003, p. 796-812.

DREHER, Marialva; TOMIO, Dilson e ULLRICH, Danielle Regina. Análise da gestão das MPEs do setor hoteleiro: o caso Blumenau, SC. In: EGEPE - ENCONTRO DE ESTUDOS SOBRE EMPREENDEDORISMO E GESTÃO DE PEQUENAS EMPRESAS. 3., 2003, Brasília. Anais... Brasília: UEM/UEL/UnB, 2003, p. 782-795.

FONTOURA, Marília. A vida dos downsizados. Revista Exame, São Paulo, v. 29, n. 10, p. 70-76, mai. 1996.

GARCIA, U.L.; GIMENEZ, F.A.P.; TOLEDO, A. Ações e Comportamento IntraEmpreendedores: uma escala de mensuração. In: ENCONTRO DE ESTUDOS SOBRE EMPREENDEDORISMO E GESTÃO DE PEQUENAS EMPRESAS. 5. 2008, São Paulo, Anais... São Paulo, 2008.

HAIR, Jr. J. F.; BABIN, B.; MONEY, A.H.; SAMOUEL, P. Fundamentos de métodos de pesquisa em administração. Porto Alegre: Bookman, 2005.

LEONE, Nilda Maria de C. P. G. As especificidades das pequenas e médias empresas. Revista de Administração, São Paulo, v. 34, n. 2, p.91-94, abril/junho 1999.

LIMA, A. A. T. de F. de C.; Meta-modelo de diagnóstico para pequenas empresas. Florianópolis, 2001. Tese (Doutorado) - Universidade Federal de Santa Catarina.

LIMA, J.B.,Temas de Pesquisa e Desafios da Produção Cientifica sobre a PME ANAIS DO I IGEPE, out./2000 p. 92-111

MORELLI, G. H. DE F. Micro e pequenas empresas: a necessidade de prioridade na política econômica. São Luiz: Sebrae, 1994.

MOURA, Luiz Rodrigo Cunha; CUNHA, Nina Rosa Silveira; MOURA, Luiz Eduardo Leite de. Avaliação da qualidade de serviços da rodabel utilizando escala servqual In: EGEPE ENCONTRO DE ESTUDOS SOBRE EMPREENDEDORISMO E GESTÃO DE PEQUENAS EMPRESAS. 4. 2005, Curitiba, Anais... Curitiba, 2005, p. 951-959.

NAISBITT, J. Paradoxo global: quanto maior a economia mundial mais poderosos são os seus protagonistas menores: nações, empresas e indivíduos. Rio de Janeiro: Campus, 1998. 
RATTNER, Henrique (Org.). Pequena empresa: o comportamento empresarial na acumulação e na luta pela sobrevivência. São Paulo: Brasiliense; Brasília: CNPq, 1985. 2 vols.

RIBEIRO NETO, Antonio Batista; CARDOSO, Rodolfo; CAULLIRAUX, Heitor Mansur. Modelos de gestão para MPE (Micro e Pequenas Empresas): o Estudo de Caso do Prêmio Top Empresarial In: EGEPE - ENCONTRO DE ESTUDOS SOBRE EMPREENDEDORISMO E GESTÃO DE PEQUENAS EMPRESAS. 4. 2005, Curitiba, Anais... Curitiba, 2005, p. 10701081.

ROESCH, Sylvia Maria Azevedo. Projetos de estágios e de pesquisa em administração, 2 ed. São Paulo: Atlas, 1999.

SANTANA, W.G.P.; GOMES, A.F. processo decisório e racionalidade em redes de pequenas empresas:uma agenda para pesquisa. In: ENCONTRO DE ESTUDOS SOBRE EMPREENDEDORISMO E GESTÃO DE MICRO E PEQUENAS EMPRESAS. 5., 2008, São Paulo, Anais... São Paulo, 2008.

SEBRAE. Estudos e pesquisas. [online]. Disponível em: http://www.sebrae.com.br/br/aprendasebrae/estudosepesquisas.asp. Acesso em: 11 de novembro de 2004 (2).

SEBRAE. Pessoal ocupado. [online]. Disponível em: http://www.sebrae.com.br/br/aprendasebrae/pessoal_ocupado.asp Acesso em: 27 de agosto de 2004. (1)

SEIXAS, R.A.; GRAVE, P.S. Diagnóstico organizacional: elementar, meu caro administrador!. Disponível em: http://www.angrad.com/cientifica/artigos/artigos_enangrad/enangrad_9.asp Acesso em: $11 \mathrm{de}$ novembro de 2004.

SOUZA, E.C.L.; FRACASSO, E.M.; LOPEZ JÚNIOR, G.S. Empreendedorismo e atitude empreendedora: conceitos e construção de escalas. In: ENCONTRO DE ESTUDOS SOBRE EMPREENDEDORISMO E GESTÃO DE PEQUENAS EMPRESAS. 5. 2008, São Paulo, Anais... São Paulo, 2008.

SOUZA, M. C. A. F.; Botelho, BARBOSA, Fábio Eduardo de Freitas; CUNHA, João Carlos da. Instrumento para auxiliar no diagnóstico em sistemas de Gestão da Qualidade baseados na NRB ISSO 9001:2000In: EGEPE - ENCONTRO DE ESTUDOS SOBRE EMPREENDEDORISMO E GESTÃO DE PEQUENAS EMPRESAS. 4. 2005, Curitiba, Anais... Curitiba, 2005, p. x-y.

VIAPIANA, C. Fatores de sucesso e fracasso na micro e pequena empresa. In: ENCONTRO DE ESTUDOS SOBRE EMPREENDEDORISMO E GESTÃO DE PEQUENAS EMPRESAS, 2., 2001, Londrina. Anais... Londrina: UEL/UEM, 2001. p 505-525. CD ROM.

WELSH, J.A.; WHITE, J.F. (1981) A small business is not a little big business. Havard Business Review. July-August 1981, Vol 59, n 4, p18-32. 


\section{IDENTIFICAÇÃO DAS PRÁTICAS DE GESTÃO DAS MICRO E PEQUENAS EMPRESAS: \\ CONSTRUINDO UMA ESCALA DE MENSURAÇÃO}

Anexo I - Índices de correlação de Spearman entre variáveis na gestão de pessoas em microempresas

\begin{tabular}{|c|c|c|c|c|c|c|c|c|c|c|c|}
\hline & $\begin{array}{l}\text { Pifferenciatȩão } \\
\text { por produto }\end{array}$ & $\begin{array}{l}\text { Novos } \\
\text { serviços }\end{array}$ & $\begin{array}{l}\text { Variedade } \\
\text { (ajustada) }\end{array}$ & $\begin{array}{l}\text { Quatiduacte } \\
\text { (ajustada) }\end{array}$ & Đivulgação & tocal & $\begin{array}{l}\text { Fidteliza } \\
\text { clientes }\end{array}$ & $\begin{array}{l}\text { Seteciona } \\
\text { divulg }\end{array}$ & Avalia satisf & $\begin{array}{l}\text { Cliemtes } \\
\text { antigos }\end{array}$ & $\begin{array}{l}\text { Pासृटco } \\
\text { (ajustado) }\end{array}$ \\
\hline $\begin{array}{l}\text { Diferenciação } \\
\text { por produto }\end{array}$ & 1,000 & $0,652(* *)$ & $0,528(* *)$ & $0,382(*)$ & $0,494(* *)$ & $0,443(* *)$ & $0,451(* *)$ & 0,181 & 0,104 & 0,073 & $-0,115$ \\
\hline $\begin{array}{l}\text { Novos } \\
\text { serviços }\end{array}$ & $0,652(* *)$ & 1,000 & $0,667(* *)$ & $0,419(*)$ & $0,369\left(^{*}\right)$ & 0,192 & 0,305 & $-0,013$ & 0,001 & 0,034 & $-0,158$ \\
\hline $\begin{array}{l}\text { Variedade } \\
\text { (ajustada) }\end{array}$ & $0,528(* *)$ & $0,667(* *)$ & 1,000 & $0,534(* *)$ & $0,542(* *)$ & 0,260 & 0,141 & $-0,159$ & 0,255 & 0,043 & 0,111 \\
\hline $\begin{array}{l}\text { Qualidade } \\
\text { (ajustada) }\end{array}$ & $0,382(*)$ & $0,419(*)$ & $0,534(* *)$ & 1,000 & $0,464(* *)$ & $0,569(* *)$ & 0,245 & 0,360 & $0,514(* *)$ & 0,231 & 0,334 \\
\hline Divulgação & $0,494(* *)$ & $0,369(*)$ & $0,542(* *)$ & $0,464(* *)$ & 1,000 & 0,238 & $0,507(* *)$ & 0,386 & $0,331(*)$ & 0,041 & $-0,074$ \\
\hline Local & $0,443(* *)$ & 0,192 & 0,260 & $0,569(* *)$ & 0,238 & 1,000 & $0,410\left(^{*}\right)$ & $0,449(*)$ & $0,366(*)$ & $\begin{array}{c}- \\
0,021\end{array}$ & 0,234 \\
\hline $\begin{array}{l}\text { Fidelização } \\
\text { de clientes }\end{array}$ & $0,451(* *)$ & 0,305 & 0,141 & 0,245 & $0,507(* *)$ & $0,410(*)$ & 1,000 & $0,565(* *)$ & $0,323(*)$ & 0,215 & $-0,003$ \\
\hline $\begin{array}{l}\text { Seleciona } \\
\text { divulg }\end{array}$ & 0,181 & $-0,013$ & $-0,159$ & 0,360 & 0,386 & $0,449(*)$ & $0,565(* *)$ & 1,000 & 0,194 & 0,218 & 0,233 \\
\hline Avalia satisf & 0,104 & 0,001 & 0,255 & $0,514(* *)$ & $0,331\left(^{*}\right)$ & $0,366(*)$ & $0,323(*)$ & 0,194 & 1,000 & 0,176 & 0,268 \\
\hline $\begin{array}{l}\text { Clientes } \\
\text { antigos }\end{array}$ & 0,073 & 0,034 & 0,043 & 0,231 & 0,041 & $-0,021$ & $-0,215$ & $-0,218$ & 0,176 & 1,000 & $-0,224$ \\
\hline $\begin{array}{l}\text { Preço } \\
\text { (ajustado) }\end{array}$ & $-0,115$ & $-0,158$ & 0,111 & 0,334 & $-0,074$ & 0,234 & $-0,003$ & 0,233 & 0,268 & $0,-$ & 1,000 \\
\hline
\end{tabular}

** Correlação significativa de 0,01 .

* Correlação significativa de 0,05 